AUTHORS:

Petal Petersen Williams ${ }^{1,2}$

Tara Carney ${ }^{1,2}$

Charles D.H. Parry ${ }^{1,3}$ iD

\section{AFFILIATIONS:}

${ }^{1}$ Alcohol, Tobacco and Other Drug Research Unit, Medical Research Council, Cape Town, South Africa

${ }^{2}$ Department of Psychiatry and Mental Health, University of Cape Town, Cape Town,

South Africa

${ }^{3}$ Department of Psychiatry, University of Stellenbosch, Stellenbosch, South Africa

\section{CORRESPONDENCE TO:}

Petal Petersen Williams

EMAIL:

petal.petersen@mrc.ac.za

DATES:

Received: 12 Nov. 2015

Revised: 30 Mar. 2016

Accepted: 02 Apr. 2016

\section{KEYWORDS:}

HIV risk; HIV intervention; alcohol; drugs

\section{HOW TO CITE:}

Petersen Williams P, Carney T, Parry $\mathrm{CDH}$. Reducing substance use and sexual risk behaviour among men who have sex with men in South Africa. S Afr J Sci. 2016;112(9/10), Art. \#2015-0425, 5 pages. http://dx.doi.org/10.17159/ sajs.2016/20150425

\section{ARTICLE INCLUDES:}

$\times$ Supplementary material

$\times$ Data set

\section{FUNDING:}

US Centers of Disease Control and Prevention (CDC): 5U2GPS001137-05

(C) 2016. The Author(s). Published under a Creative Commons Attribution Licence.

\title{
Reducing substance use and sexual risk behaviour among men who have sex with men in South Africa
}

Men who have sex with men have been identified as a population at risk of acquiring and transmitting
HIV. Studies in South Africa have reported a high prevalence of HIV, as well as high levels of alcohol and
other drug use, among men who have sex with men, and the use of substances (alcohol and drugs) to
facilitate their sexual encounters. Since 2007, interventions focused on prevention have been rolled out
to vulnerable men who have sex with men and who also use alcohol or other drugs. The interventions
include community-based outreach; provision of information on HIV/AIDS, substance abuse, and safer
sex practices; and the development of risk-reduction plans. Among 195 men who participated in our
study, there were significant reductions in the proportion who used cannabis and ecstasy, including
the use of these drugs during sex. No reduction was observed in the use of any other substances. In
general, after the intervention our participants reported less frequent use of alcohol and drugs and greater
engagement in safer sexual practices. Despite these encouraging findings, the combination of substance
use while engaging in sex had actually increased. The study findings suggest that interventions that
target men who have sex with men, and who use alcohol and other drugs, could reduce risk behaviours
in this population.
Significance:
- Contributes to knowledge about risk reduction strategies.
- Describes strategies for reducing drug and sexual harm among men who have sex with men.

\section{Introduction}

South Africa is a country considered to have the worst HIV epidemic worldwide. In 2012, an estimated $12.2 \%$ (6.4 million persons) of the population were HIV-positive. ${ }^{1}$ Although researchers have not determined the national HIV prevalence among men who have sex with men (MSM) in South Africa, this group has been identified as being at particular risk of acquiring HIV. Several small-scale studies conducted among MSM have reported HIV prevalence rates of between $10.4 \%$ and $43.6 \% .^{2-5}$

Local research has also documented high levels of drug use among MSM, and the use of drugs to facilitate sexual encounters. ${ }^{6}$ The link between drug use and HIV risk behaviour among MSM (including multiple sexual partners, unprotected anal intercourse, condom use and transactional sex) has been established in international literature. ${ }^{7}$ The need to develop and accelerate the rollout of evidence-based interventions to address the related risks in this population has been clearly articulated. ${ }^{7}$ South African studies have also identified the need for targeted risk reduction interventions to address the link between substance use and HIV risk behaviour among MSM. ${ }^{8,9}$ Interventions focusing on risk reduction strategies among substance-using MSM have been shown to be successful in reducing risky sexual behavior. ${ }^{10,11}$

MSM in South Africa remain under-served in terms of HIV prevention and treatment services, despite studies revealing high risk of HIV infection among this population. In addition to the incidental use of drugs during sexual encounters, drugs are also used specifically to enhance sexual interactions. Aspects of such usage include enhancing the sexual experience, increasing sexual arousal, facilitating sexual encounters, increasing the capacity to engage in particular sexual activities, increasing the length of sexual interactions and facilitating sex work. ${ }^{12}$ According to Mclntyre et al. ${ }^{12}$, despite drug use being well documented among MSM in South Africa, there are few programmes that target this aspect of HIV risk. McIntyre et al. argue that a range of possible interventions already exist and could be developed to target drug-using MSM. These include a specific focus on drug use in the context of sex parties, group sex and sex-on-site venues; non-judgemental materials focusing on risk reduction when using drugs; information about the risks of combining different substances (such as 'poppers' - amyl nitrate or butyl nitrate - and erectile dysfunction drugs); and the development of MSM-specific drug use risk reduction counselling training for health workers and people working with drug users. ${ }^{12}$

South Africa's second National Drug Master Plan gave prominence to the need to address drug abuse as part of broader HIV prevention efforts. ${ }^{13}$ However, interventions targeting MSM to address drug use and sexual risk behaviour remain scarce in South Africa. Recently, the feasibility of delivering large-scale interventions to this particular group has been demonstrated locally. ${ }^{14}$ The aim of our study was to test whether an intervention aimed at MSM who use substances (alcohol and other drugs) could affect risky substance use and sexual behaviour.

\section{Method}

In 2007, in collaboration with a local NGO in Pretoria (OUT LGBT), an initiative was begun to implement a number of harm-reduction strategies for MSM who use alcohol and other drugs. This NGO was selected because of its expertise and extensive experience working with the target population. Important components of the intervention included community outreach, distribution of condoms and lubricants, HIV risk assessment and risk reduction counselling, expanded access to HIV counselling and testing, care and treatment of HIV and sexually transmitted 
diseases, and referrals to substance abuse treatment and other social services. The intervention also aimed to build referral networks, decrease stigma among service providers, and influence NGO practices and government policies on drugs and HIV. These activities were in line with the six core elements defined in the Technical Guidance on Combination HIV Prevention for effective MSM programmes as released by the Office of the U.S. Global AIDS Coordinator in May 2011, as part of the U.S. President's Emergency Plan for AIDS Relief's overall prevention strategy. ${ }^{15}$

\section{Participants and data collection}

The intervention was conducted in various areas in and around Johannesburg and Pretoria in Gauteng, and around Nelspruit in Mpumalanga. A number of locations were targeted, including gay and lesbian pride events, gay clubs and areas known to be frequented by MSM, and through site work at the NGO's premises or clinics and wellness centres, where the NGO made use of negotiated spaces within such clinics or centres.

To be included in the study, participants had to be 16 years or older. They also had to be self-reported MSM who were using alcohol and/ or drugs, regardless of whether they self-identified as gay, bisexual or heterosexual, and regardless of HIV status. The quantity of alcohol or drugs used by participants was not set as an exclusion criterion. Participants who were eligible for inclusion and willing to participate signed an informed consent form, and the principles of the Declaration of Helsinki were adhered to. Peer outreach workers completed a face-toface baseline questionnaire with participants, to record risk behaviours. A risk-reduction plan was developed with each participant, which took into account risks related to injection and non-injection drug use, sexrelated risks and HIV testing.

Intervals between follow-up appointments were not specified. In some instances outreach workers made appointments for follow-up at a time that suited the participants, and in other instances follow-up appointments occurred spontaneously when outreach workers met up with participants at various events or social gatherings. At follow-up, the same questionnaire that had been administered at baseline was completed again. Also at follow-up, clients were asked the frequency of risk behaviour or its reduction, and whether they had been tested for HIV or asked their partner to test for HIV or encouraged a friend to be tested. Behaviour change was thus self-reported rather than observed.

In the areas where the intervention was delivered, MSM participants spoke Sepedi, Setswana, Afrikaans or English. Questionnaires were administered in English, with outreach workers translating difficult concepts where necessary. Our study is part of a bigger study that includes four provinces of South Africa. Ethical approval for conducting the study was granted by the Health Research Committee of the University of Stellenbosch.

\section{Intervention}

The NGO received training on an intervention that was based on a local adaptation of the World Health Organization's Training Guide for HIV Prevention Outreach to Injecting Drug Users. ${ }^{16}$ The adaptation lessened the focus on injection drug use related behaviours, and placed greater focus on substance-related sexual HIV risk behaviour. The adapted manual also emphasised drugs commonly used in South Africa. The NGO recruited peer outreach workers on a volunteer basis and they were paid a modest stipend. Project coordinators were appointed in the organisation to ensure the smooth running of the project, and to liaise between the NGO and the Medical Research Council project manager.

The intervention included community-based outreach and provision of information on HIV/AIDS, substance use, and safer sex practices. Each MSM who participated developed a personalised HIV risk reduction plan with the help of the outreach workers. The plans were followed up and reassessed with the participants. In addition to the provision of risk reduction counselling, the intervention included the provision of HIV counselling and testing services and referrals to treatment and care for substance abuse, HIV or sexually transmitted infections, and other social services. Intervention services were monitored on a monthly basis and evaluated biannually.

\section{Data analysis}

Demographic information was collected at the first contact (baseline), and descriptive statistics were calculated for these variables. Data on substance use and sexual risk behaviour were also collected at baseline and at each follow-up appointment. We assessed the distribution of behavioural data using the Shapiro-Wilks test of normality, and the results indicated that the data were non-normally distributed $(p<0.001)$. Therefore, we conducted bivariate analysis for continuous variables (number of sex partners, number of times engaged in sex, number of times had unprotected sex, number of times traded sex, and number of times had sex under the influence of substances). The Wilcoxon signed rank test was used to determine whether selfreported differences between baseline and follow-up were statistically significant. For categorical variables (types of substances used, either in general or during sex), we assessed the differences in proportions with the chi-square test of association. All statistics were analysed at $95 \%$ confidence intervals, and data analysis was performed with SPSS version 21

\section{Results}

\section{Sample characteristics}

The early years of implementation of the intervention were 2007 to 2009. This paper reports on implementation activities between 2010 and 2012. Baseline information was collected from 195 MSM who were recruited into the study, whose substance abuse and HIV risk profile was assessed. The participants then received an intervention and were subsequently followed up. Of these, $27.7 \%$ had one repeat contact with outreach workers, 30.3\% had two repeat contacts, $29.7 \%$ had three repeat contacts and $10.8 \%$ had four repeat contacts. The data presented are for first contact (baseline) and the final follow-up contact for a particular participant. The median age of the MSM participants was 27 years, and participants had a median of 12 years of formal education. The majority of participants in our study were employed (56.4\%) and single (66.7\%). Table 1 shows the demographic data.

Table 1: $\quad$ Summary statistics of participants' demographic data $(N=195)$

\begin{tabular}{|c|c|c|}
\hline & $N$ & $\%$ \\
\hline \multicolumn{3}{|l|}{ Occupation } \\
\hline Unemployed & 41 & 21.0 \\
\hline Employed & 110 & 56.4 \\
\hline Student or pupil & 39 & 20.0 \\
\hline Other & 4 & 2.1 \\
\hline \multicolumn{3}{|l|}{ Marital Status } \\
\hline Single & 130 & 66.7 \\
\hline Partnered & 53 & 27.2 \\
\hline Married, opposite sex & 7 & 3.6 \\
\hline Married, same sex & 1 & 0.5 \\
\hline Divorced or separated & 3 & 1.5 \\
\hline Age (years) & 27 (median) & $31(18-49)^{\mathrm{a}}$ \\
\hline Education (years) & 12 (median) & $6(7-13)^{\mathrm{a}}$ \\
\hline
\end{tabular}

${ }^{a}$ Interquartile range 


\section{Substance use}

We calculated the proportion of participants who used each substance at baseline (time ${ }_{1}$ ) and at last follow-up (time ${ }_{2}$ ), and the difference between these two time points (Table 2). Substances used by less than $5 \%$ of the sample were excluded. Only four of the 195 participants reported injection drug use (at baseline). There were significant reductions in the proportion of MSM who used cannabis $(p=0.009)$ and ecstasy $(p=0.043)$ from time ${ }_{1}$ to time ${ }_{2}$. No significant differences were observed for the use of alcohol, cocaine, inhalant, amyl or butyl nitrate, and overthe-counter or prescription drugs from time ${ }_{1}$ to time $_{2}$.

Table 2: $\quad$ Prevalence of substance use at time ${ }_{1}$ and time ${ }_{2}$

\begin{tabular}{|c|c|c|c|c|}
\hline Substance & $N\left(\right.$ time $\left._{1}\right)$ & $N\left(\right.$ time $\left._{2}\right)$ & $z$ & $p$ \\
\hline Alcohol & 193 & 191 & $0.81(-0.014 ; 0.034)$ & 0.417 \\
\hline Cannabis & 126 & 101 & $2.61(0.03 ; 0.227)$ & $0.009^{*}$ \\
\hline Cocaine & 14 & 12 & $0.40(-0.039 ; 0.059)$ & 0.689 \\
\hline Ecstasy & 33 & 19 & $2.02(0.003 ; 0.137)$ & $0.043^{*}$ \\
\hline Inhalants & 29 & 25 & $0.57(-0.049 ; 0.089)$ & 0.569 \\
\hline Amyl or butyl nitrate & 30 & 32 & $0.27(-0.08 ; 0.06)$ & 0.785 \\
\hline $\begin{array}{l}\text { Over-the-counter or } \\
\text { prescription drugs }\end{array}$ & 10 & 3 & $1.61(-0.006 ; 0.066)$ & 0.107 \\
\hline
\end{tabular}

There was also a highly significant change in the frequency of substance use $(p \leq 0.001)$, with participants using substances less frequently after the intervention. At time, $30.3 \%$ reported daily use of substances, whereas only $13.8 \%$ reported daily use at time, with a greater number of participants using substances only once a week or less (Table 3).

Table 3: Frequency of substance use at time and time $_{2}$

\begin{tabular}{l|c|c}
\hline \hline \multicolumn{1}{c|}{ Frequency of use } & time $_{1}$ & time $_{2}$ \\
\hline Once a week or less & $16.4 \%$ & $31.8 \%$ \\
\hline 2-6 days a week & $50.8 \%$ & $54.4 \%$ \\
\hline Daily & $30.3 \%$ & $13.8 \%$ \\
\hline
\end{tabular}

The use of more than one substance (polydrug use) was recorded at time $_{1}$ and time $e_{2}$. After the intervention, $35.9 \%$ of participants reported no change in the number of different substances used, and $28.2 \%$ had actually increased the number of different substances they used. However, 35.9\% had decreased the number of different substances used between time ${ }_{1}$ and time ${ }_{2}$ (Table 4 ).

Table 4: $\quad$ Change in drug and alcohol use

\begin{tabular}{l|c|c}
\hline \hline \multicolumn{1}{|c|}{ Type of change } & $\boldsymbol{N}$ & $\%$ \\
\hline No change & 70 & 35.9 \\
\hline Increase in AODs by number of substances: & & \\
\hline 1 & 44 & 22.6 \\
\hline 2 & 8 & 4.1 \\
\hline 3 & 2 & 1.0 \\
\hline 4 & 1 & 0.5 \\
\hline Decrease in AODs by number of substances: & & \\
\hline 1 & 35 & 17.9 \\
\hline 2 & 30 & 15.4 \\
\hline 3 & 5 & 2.6 \\
\hline 4 & 0 & 0.0 \\
\hline
\end{tabular}

Key: AOD, alcohol and other drugs

\section{Sexual risk behaviour}

Following the intervention, participants had significantly fewer partners $(z=-6.663 ; p \leq 0.001)$ but had sex with these partners more frequently (Table 5). Frequency of receptive anal sex increased significantly $(z=-5.551 ; p \leq 0.001)$; frequency of insertive anal sex increased significantly $(z=-2.707 ; p=0.007)$ and frequency of oral sex also increased significantly $(z=-5.409 ; \quad p \leq 0.001)$. However, despite having sex more frequently, the participants reported having safer sex following the intervention. The frequency of condom usage increased significantly for receptive anal sex $(z=-7.960 ; p \leq 0.001)$, insertive anal $\operatorname{sex}(z=-6.094 ; p \leq 0.001)$ and oral $\operatorname{sex}(z=-4.411 ; p \leq 0.001)$.

Table 5: Sexual risk behaviour reported at time ${ }_{1}$ and time ${ }_{2}$

\begin{tabular}{l|c|c|c|c}
\hline \hline \multicolumn{1}{c|}{ Sexual risk } & $\begin{array}{c}\text { Time }_{1} \\
\text { Median (IQR)\% }\end{array}$ & $\begin{array}{c}\text { Time }_{2} \\
\text { Median (IQR)\% }\end{array}$ & $z$ & $p$ \\
\hline Number of sex partners & $3(1-15)$ & $2(1-17)$ & -6.663 & $0.000^{*}$ \\
\hline $\begin{array}{l}\text { Times had receptive } \\
\text { anal sex }\end{array}$ & $6(0-31)$ & $10(0-45)$ & -5.551 & $0.000^{*}$ \\
\hline $\begin{array}{l}\text { Times had insertive } \\
\text { anal sex }\end{array}$ & $8(0-40)$ & $10(0-40)$ & -2.707 & $0.010^{*}$ \\
\hline \begin{tabular}{l} 
Times had oral sex \\
\hline $\begin{array}{l}\text { Times used condoms for } \\
\text { receptive anal sex }\end{array}$
\end{tabular} & $10(0-60)$ & $19(0-60)$ & -5.409 & $0.000^{*}$ \\
\hline $\begin{array}{l}\text { Times used condoms for } \\
\text { insertive anal sex }\end{array}$ & $3(0-26)$ & $7(0-45)$ & -7.960 & $0.000^{*}$ \\
\hline $\begin{array}{l}\text { Times used condoms for } \\
\text { oral sex }\end{array}$ & $0(0-7)$ & $0(0-26)$ & -4.411 & $0.000^{*}$ \\
\hline $\begin{array}{l}\text { Times traded sex for } \\
\text { money }\end{array}$ & $0(0-25)$ & $0(0-39)$ & -2.005 & 0.050 \\
\hline
\end{tabular}

$*, p<0.05$

Key: IQR, interquartile range

\section{Sexual risk and substance use}

As shown in Table 6, there were significant reductions in the proportion of participants who used cannabis $(p=0.005)$ and ecstasy $(p=0.04)$ during sex, from time to time ${ }_{2}$. No significant differences were observed between time ${ }_{1}$ and time ${ }_{2}$ for the use of alcohol, cocaine, inhalants, amyl or butyl nitrate, and over-the-counter or prescription drugs during sex. However, participants engaged in sex while using drugs and alcohol more frequently after the intervention (median sexual events: time $=10$; time $_{2}=18 ; z=-3.465 ; p=0.001$ ). In total, $34.4 \%$ of participants reported no change in the number of different substances used during sex, whereas $28.7 \%$ had increased the number of different substances used during sex, and $36.9 \%$ had decreased the number of different substances used during sex (Table 7).

Table 6: $\quad$ Sexual risk and substance use reported at time ${ }_{1}$ and time ${ }_{2}$

\begin{tabular}{l|c|c}
\hline \hline \multicolumn{1}{c|}{ Substance } & $\boldsymbol{N}\left(\right.$ Time $\left._{1}\right)$ & $\boldsymbol{N}\left(\right.$ Time $\left._{2}\right)$ \\
\hline Alcohol during sex & 189 & 187 \\
\hline Cannabis during sex & 129 & 101 \\
\hline Cocaine during sex & 15 & 10 \\
\hline Ecstasy during sex & 32 & 18 \\
\hline Inhalants during sex & 28 & 25 \\
\hline Amyl/butyl nitrate during sex & 27 & 31 \\
\hline OTC/Pre during sex & 9 & 3 \\
\hline
\end{tabular}


Table 7: Change in alcohol and drug use during sex

\begin{tabular}{l|c|c}
\hline \hline \multicolumn{1}{c|}{ Type of change } & N & $\%$ \\
\hline No change & 67 & 34.4 \\
\hline Increase in AODs by number of substances: & & \\
\hline 1 & 45 & 23.1 \\
\hline 2 & 9 & 4.6 \\
\hline 3 & 1 & 0.5 \\
\hline 4 & 1 & 0.5 \\
\hline Decrease in AODs by number of substances: & & \\
\hline 1 & 34 & 17.4 \\
\hline 2 & 32 & 16.4 \\
\hline 3 & 6 & 3.1 \\
\hline 4 & 0 & 0.0 \\
\hline
\end{tabular}

Key: AODs, alcohol and other drugs

\section{Discussion}

MSM participants in our study engaged in multiple alcohol or other drug use and sexual risk behaviours. However, as reported in an earlier phase of this project ${ }^{14}$, participants were receptive to NGOs delivering HIV prevention and substance risk reduction services, and were willing to develop individual risk reduction strategies with outreach workers. Other intervention studies with substance-using MSM have also demonstrated that it is possible to enrol and retain MSM in intervention studies. ${ }^{7}$

Our study showed that the only significant reduction after the intervention was the proportion of MSM who used cannabis and ecstasy, including the use of these drugs during sex. However, participants did report less frequent alcohol or other drug use at Time ${ }_{2}$. Additionally, more participants had reduced the diversity of substances used relative to the number of participants who increased their polysubstance use (including the use of substances during sex). Most importantly, participants reported safer sex practices following the intervention, including having fewer sexual partners and more frequent condom use during sex. However, after the intervention, participants engaged in sex while using drugs and alcohol more frequently than they had before the intervention. Other studies have similarly found that risk reduction, rather than 'abstinence only' strategies, are an effective approach for this population. ${ }^{17}$

Evidence suggests that behavioural interventions to reduce risk for sexual transmission of HIV among MSM can be effective. A metaanalysis that reviewed HIV behavioural interventions for reducing sexual risk behaviour of MSM found, as did our study, that interventions were associated with a significant decrease in unprotected anal intercourse and number of sexual partners, and with a significant increase in condom use during anal intercourse. ${ }^{11} \mathrm{~A}$ Cochrane review found that these interventions can lead to significant risk reduction among MSM, specifically a reduction in unprotected anal intercourse. ${ }^{18}$ However, the authors distinguish between individual, group and community-level interventions; not all interventions are equally effective. ${ }^{18}$

A randomised controlled trial was conducted in the U.S. to test a cognitivebehavioural group intervention outside treatment centres, focusing on reducing sexual risk behaviour of substance-using MSM. ${ }^{19}$ The study found the intervention was no more efficacious than the control condition in reducing sexual risk behaviours or substance use. Instead, substantial reductions occurred in both the intervention and control groups. ${ }^{19}$ In another trial examining the effects of motivational interviews on club drug use and risky sex, with MSM participants who did not seek treatment, motivational interviews were not found to be effective in reducing risky sexual behaviour. ${ }^{20}$ However, the motivational interviews did result in significant reductions in club drug use in the intervention group compared with the control group - but only among participants with lower severity of drug dependence. ${ }^{20}$ Based on these findings, it appears that although risk-reduction interventions have demonstrated their ability to reduce risky behaviour, further research is needed to determine which interventions are most efficacious. ${ }^{7}$

The findings of our study are subject to the following limitations. Firstly, risk behaviours were self-reported by the MSM participants and might be subject to social desirability or other biases. Although peer outreach workers established relationships with the participants and this may have facilitated honest self-reporting, we did not confirm the self-reports by biological testing for substance use. Secondly, questionnaires were administered in English, with outreach workers translating difficult concepts where necessary. This approach is not as robust as written and tested translation, and interpretation errors can occur when English-medium tools are used with non-native English speakers. Thirdly, there was no comparison group and all participants received the same intervention. Thus, it was not possible to conclude that changes in risky behaviour were the result of the intervention. Finally, we recruited participants only from certain areas in and around Gauteng and Mpumalanga, and the results should not be generalized to other provinces and areas. As reported in other studies, our participants were recruited by outreach workers from local MSM NGOs, which further limits the generalizability of the findings. ${ }^{21}$

Despite these limitations, the findings of our study (and others) demonstrate that interventions targeting substance-using MSM can reduce risk behaviour among this population. In South Africa, programmes that target MSM for HIV prevention, treatment and care are not well developed. Where they do occur, they are provided mostly by NGOs or community-based organisations in specific geographical areas and have not been up-scaled across the country. ${ }^{12}$ As a result there remains a need to offer widespread integrated services related to alcohol or drug use and HIV risk, especially where community-based outreach is available and is tailored for MSM who use alcohol or other drugs. What the current study has shown is that while interventions with MSM can have a positive effect in reducing HIV risk behaviours (such as having sex without a condom), the effects on substance-use behaviour are modest. More work is needed to determine how substance abuse behaviour among MSM can be reduced effectively.

\section{Authors' contributions}

C.P. designed the study and was the project leader. P.P.W. and T.C. performed the analysis, and P.P.W. wrote the first draft of the manuscript. All authors contributed to and approved the final manuscript.

\section{References}

1. Shisana O, Rehle T, Simbayi LC, Zuma K, Jooste S, Zungu N, et al. South African national HIV prevalence, incidence and behaviour survey, 2012. Cape Town: HSRC Press; 2014.

2. Burrell E, Baral S, Beyrer C, Wood R, Bekker LG. Abstract LBPE1195. IAS Conference 2008; Mexico City, Mexic0, 3-8 August 2008.

3. Burrell E, Mark D, Grant R, Wood R, Bekker LG. Sexual risk behaviours and HIV-1 prevalence among urban men who have sex with men in Cape Town, South Africa. Sex Health. 2010;7:149-153. http://dx.doi.org/10.1071/ SH09090

4. Lane T, Fisher Raymond H, Dladla S, Rasethe J, Struthers H, McFarland W, et al. HIV prevalence among men who have sex with men in Soweto, South Africa: Results from the Soweto men's study. AIDS Behav. 2011;15:626634. http://dx.doi.org/10.1007/s10461-009-9598-y

5. Metcalf C, Rispel L. Exposing a hidden HIV epidemic among men who have sex with men. HSRC Review. 2009;7(2):4-5. http://dx.doi.org/10.1016/ S0968-8080(09)33442-4

6. Parry CDH, Petersen P, Dewing S, Carney T, Needle R, Kroeger K, et al. Rapid assessment of drug related HIV risk among men who have sex with men in three South African cities. Drug Alcohol Depen. 2008;95:45-53. http://dx.doi. org/10.1016/j.drugalcdep.2007.12.005

7. Santos GM, Das M, Colfax GN. Interventions for non-injection substance use among men who have sex with men: What is needed. AIDS Behavior. 2011;15:S51-S56. http://dx.doi.org/10.1007/s10461-011-9923-0 
8. Lane T, Shade SB, Mclntyre J, Morin SF. Alcohol and sexual risk behavior among men who have sex with men in South African township communities. AIDS Behavior, 2008;12(1):78-85 http://dx.doi.org/10.1007/s10461-0089389-x

9. Parry CDH, Petersen P, Carney T, Needle R. Opportunities for enhancing and integrating HIV and drug services for vulnerable drug using populations in South Africa. Int J Drug Policy. 2010;21(4):289-295. http://dx.doi. org/10.1016/j.drugpo.2009.11.008

10. Mausbach BT, Semple SJ, Strathdee SA, Zians J, Patterson TL. Efficacy of a behavioral intervention for increasing safer sex behaviors in HIVpositive MSM methamphetamine users: Results from the EDGE study. Drug Alcohol Depen. 2007;87(2-3):249-257. http://dx.doi.org/10.1016/j. drugalcdep.2006.08.026

11. Herbst JH, Sherba RT, Crepaz N, DeLuca JB, Zohrabyan L, Stall RD, et al. A meta-analytic review of HIV behavioral interventions for reducing sexual risk behavior of men who have sex with men. J Acq Immun Def Synd. 2005;39(2):228-241.

12. McIntyre J, Jobson G, Struthers H, De Swardt G, Rebe K. Rapid assessment of HIV prevention, care and treatment programming for MSM in South Africa. Assessment Report 2013. Johannesburg: Anova Health Institute. http:// dx.doi.org/10.1007/s10461-012-0328-5

13. Department of Social Development. National drug master plan 2006-2011. Republic of South Africa, Pretoria: Department of Social Development; 2007.

14. Petersen Williams P, Carney T, Parry $\mathrm{CDH}$, Plüddemann A. Intervening to identify and reduce drug use and sexual HIV risk patterns among men who have sex with men in three provinces in South Africa. J Subst Use. 2014;19(1-2):141-146. http://dx.doi.org/10.3109/14659891.2012.760009
15. The U.S. President's Emergency Plan for AIDS Relief. Technical guidance on combination HIV prevention. [Document on the Internet.] c 2011 [Cited 2011 September 14]. Available from http://www.pepfar.gov/documents/ organization/164010.pdf.

16. Burrows $D$. Training guide for HIV prevention outreach to injecting drug users: Workshop manual. Geneva: World Health Organization, Department of HIV/ AIDS; 2004.

17. Seal DW, Kelly JA, Bloom FR, Stevenson LY, Coley BI, Broyles LA, et al. HIV prevention with young men who have sex with men: What young men themselves say is needed. AIDS Care. 2000;12(1):5-26. http://dx.doi. org/10.1080/09540120047431

18. Johnson WD, Diaz RM, Flanders WD, Goodman M, Hill AN, Holtgrave D, et al. Behavioral interventions to reduce risk for sexual transmission of HIV among men who have sex with men. Cochrane DB Syst Rev. 2008;3, Art. \#CD001230. http://dx.doi.org/10.1002/14651858.CD001230.pub2

19. Mansergh G, Koblin BA, McKirnan DJ, Hudson SM, Flores SA, Wiegand RE, et al. An intervention to reduce HIV risk behavior of substance-using men who have sex with men: A two-group randomized trial with a nonrandomized third group. PLoS Med. 2010;7(8), Art. \#e1000329. http://dx.doi.org/10.1371/ journal.pmed. 1000329

20. Morgenstern J, Bux DA Jr, Parsons J, Hagman BT, Wainberg M, Irwin T. Randomized trial to reduce club drug use and HIV risk behaviors among men who have sex with men. J Consult Clin Psychol. 2009;77(4):645-656. http:// dx.doi.org/10.1037/a0015588

21. Thomas B, Mimiaga MJ, Mayer KH, Johnson CV, Menon S, Chandrasekaran $\mathrm{V}$, et al. HIV prevention interventions in Chennai, India: Are men who have sex with men being reached? AIDS Patient Care ST. 2009;23(11):981-986. http:// dx.doi.org/10.1089/apc.2009.0092 